\title{
African forest elephant social networks: fission-fusion dynamics, but fewer associations
}

\author{
Stephanie G. Schuttler ${ }^{1, *}$, Alden Whittaker ${ }^{2}$, Kathryn J. Jeffery ${ }^{3,4,5}$, Lori S. Eggert ${ }^{1}$ \\ ${ }^{1}$ Division of Biological Sciences, 226 Tucker Hall, University of Missouri, Columbia, MO 65211, USA \\ ${ }^{2}$ Zakouma National Park, African Parks Network, PO Box 510, N'Djaména, Republic of Chad \\ ${ }^{3}$ Agence Nationale des Parcs Nationaux, BP20379, Libreville, Gabon \\ ${ }^{4}$ School of Natural Sciences, University of Stirling, Stirling FK9 4LA, UK \\ ${ }^{5}$ Institut de Recherche en Ecologie Tropicale, BP13354, Libreville, Gabon
}

\begin{abstract}
For animal species with dynamic interactions, understanding social patterns can be difficult. Social network analysis quantifies associations and their intensity between individuals within a population, revealing the overall patterns of the society. We used networks to test the hypothesis that the elusive African forest elephant Loxodonta cyclotis exhibits fission-fusion social dynamics, similar to other elephant species. We observed associations between individuals in savanna clearings in Lopé National Park, Gabon, in 2006, 2008, and 2010. When possible, dung was collected from individuals for genetic analyses using 10 microsatellite loci and the mitochondrial DNA control region. Using simple ratio association indices, networks were created for each year, wet and dry seasons, individuals detected at least twice, and for all females. We identified 118 unique adult females, for 40 of which we obtained genetic information. Networks had low densities, many disconnected components, short average path lengths, and high clustering coefficients. Within components, average relatedness was $0.093 \pm 0.071$ (SD) and females appeared to share mitochondrial haplotypes. We detected 1 large component consisting of 22 adult females, but there were few preferred associations ( 8 of $65,12.3 \%$ ). No seasonal or yearly differences were observed. Our results substantiate fission-fusion dynamics in forest elephants; however, the networks are more disconnected than those for other elephant species, possibly due to poaching and ecological constraints in the forest environment.
\end{abstract}

KEY WORDS: Social networks $\cdot$ Social structure $\cdot$ Loxodonta cyclotis $\cdot$ Fission-fusion $\cdot$ Elephants

\section{INTRODUCTION}

Individuals within a population rarely interact randomly. Ecological pressures such as competition influence individuals to develop strategies to maximize their fitness. The range of interactions varies from antagonistic, where individuals defend territories aggressively, to cooperative, in which conspecifics gain benefits such as predator defense through working together (Wrangham 1980, Krebs \& Davies 1997). Social structure affects how individuals exploit habitats (Hoelzel 1993), transfer knowledge (Weimerskirch et al. 2010), transmit diseases (Hamede et al. 2009), and search for mates (Ortega et al. 2003,
Rossiter et al. 2012), and, therefore, has evolutionary consequences and implications for conservation.

Some species change group sizes over time and/or space, presenting a challenge to understanding interactions. Chimpanzees (Pan troglodytes; Lehmann \& Boesch 2004), bats (Kerth \& Konig 1999, Willis \& Brigham 2005), African buffalo (Synerus caffer; Prins 1989), dolphins (Parra et al. 2011), and African savanna elephants (Loxodonta africana; Archie et al. 2006) have fission-fusion social systems, where group composition and structure can change monthly, daily, or hourly in response to resources or group dynamics. Social network analysis is an effective tool for studying and comparing social systems, as metrics 
can be quantified and visualized (Croft et al. 2008, Wey et al. 2008, Sih et al. 2009, Croft et al. 2011). We used network analysis to elucidate the social structure of the African forest elephant Loxondonta cyclotis, an elusive species thought to have fission-fusion dynamics.

Two species of African elephant are recognized: savanna and forest (Rohland et al. 2010). In savanna elephants, related females form family groups that repeatedly join and separate from other groups (Moss 1988, Wittemyer et al. 2005, Archie et al. 2006). Family groups are important for fitness. Females rear young as a group (Lee 1987), and intact groups are more effective at forming defensive postures in response to playback calls from lions (McComb et al. 2011). The oldest member, the matriarch, retains knowledge about the landscape important for the group's survival (McComb et al. 2001). In poached populations, where social structure is disrupted, groups have lower reproductive output and higher stress levels (Gobush et al. 2008), with potentially long-term negative consequences for decisionmaking abilities (Shannon et al. 2013).

Less is known about forest elephant social structure, as their dense and remote habitat makes it difficult to conduct behavioral studies. Observational studies at forest clearings or in savanna patches within forested regions suggest that sociality is different; groups are typically composed of an adult female and her calves (White et al. 1993, Turkalo et al. 2013). This suggests that it may be disadvantageous for individuals to navigate the forest in groups, possibly because of increased difficulties in foraging and exploiting resources (Sukumar 2003). Forest elephant diet is largely composed of fruits (CamposArceiz \& Blake 2011); fruiting trees may be depleted more rapidly when visited by large groups.

Evidence suggests that forest elephants may have more extensive associations than indicated by group sizes alone and by fission-fusion dynamics (Fishlock \& Lee 2013). Studies at natural clearings with mineral deposits that attract elephants show that females sometimes associate with other groups, and that individuals are not always in the same group or in groups of the same size (Turkalo \& Fay 1996, Fishlock et al. 2008). A genetic network derived from non-invasive sampling of dung found in groups suggests that some elephants have larger associations than observed and that associations are largely based on matrilines (Schuttler et al. 2014).

Collectively, these studies suggest that individuals may have more associates than is indicated by observational studies and that group sizes vary. How- ever, it is unknown how individuals are connected throughout the population and if associations are based on kinship. Using observations, genetic data, and network analyses, we tracked individual forest elephants to quantify the number of associates and the quality of relationships. We tested the hypotheses that forest elephants have a social structure with fission-fusion dynamics where kinship predicts associations, group sizes change over time and space, and associations are more extensive than observed within groups. We predicted that kin-based social structure exists, but group sizes and the number of associates would be smaller than for Asian elephants Elephas maximus and African savanna species due to ecological constraints in the forest.

\section{MATERIALS AND METHODS}

\section{Field methods}

Field research was conducted in northeastern Lopé National Park (LNP), Gabon, at the Station d'Etudes des Gorilles et Chimpanzees (SEGC; Fig. 1). LNP consists of mature forest, but the northeastern section contains a mosaic of diverse forest types and savannas that facilitate observations of elephants (White et al. 1993). Elephant (Loxodonta cyclotis) densities are estimated at approximately 3.0 elephants $\mathrm{km}^{-2}$ (White 1994). Two dry seasons (June to mid-September and December to January/February) and 2 wet seasons (September to November and February to May) are recognized, although inter-annual variation occurs (Fig. S1 in the Supplement at www.int-res.com/articles/ suppl/n025p165_supp.pdf).

Observations were made in 2006 (1 March to 17 September), 2008 (8 August to 7 November) and 2010 (17 February to 12 May). Circuits were conducted by vehicle on roads (Fig. 1) at dusk and dawn and, opportunistically, after rainfall. Routes and circuits were changed daily to avoid spatio-temporal sampling biases. Individuals were considered to be in the same group if they were observed within $250 \mathrm{~m}$ of one another. This distance is a compromise between $50 \mathrm{~m}$ (Morgan \& Lee 2007), which was too small for LNP, and those used in savanna elephant studies (500 $\mathrm{m}$ from center of aggregation; Wittemyer et al. 2005, Archie et al. 2006). Group differentiation was not difficult, as groups were usually at least several kilometers apart, and there were few groups (3\%, 8 of 275) for which membership was uncertain.

All individuals were photographed and identified using morphological characteristics (ear tears and 

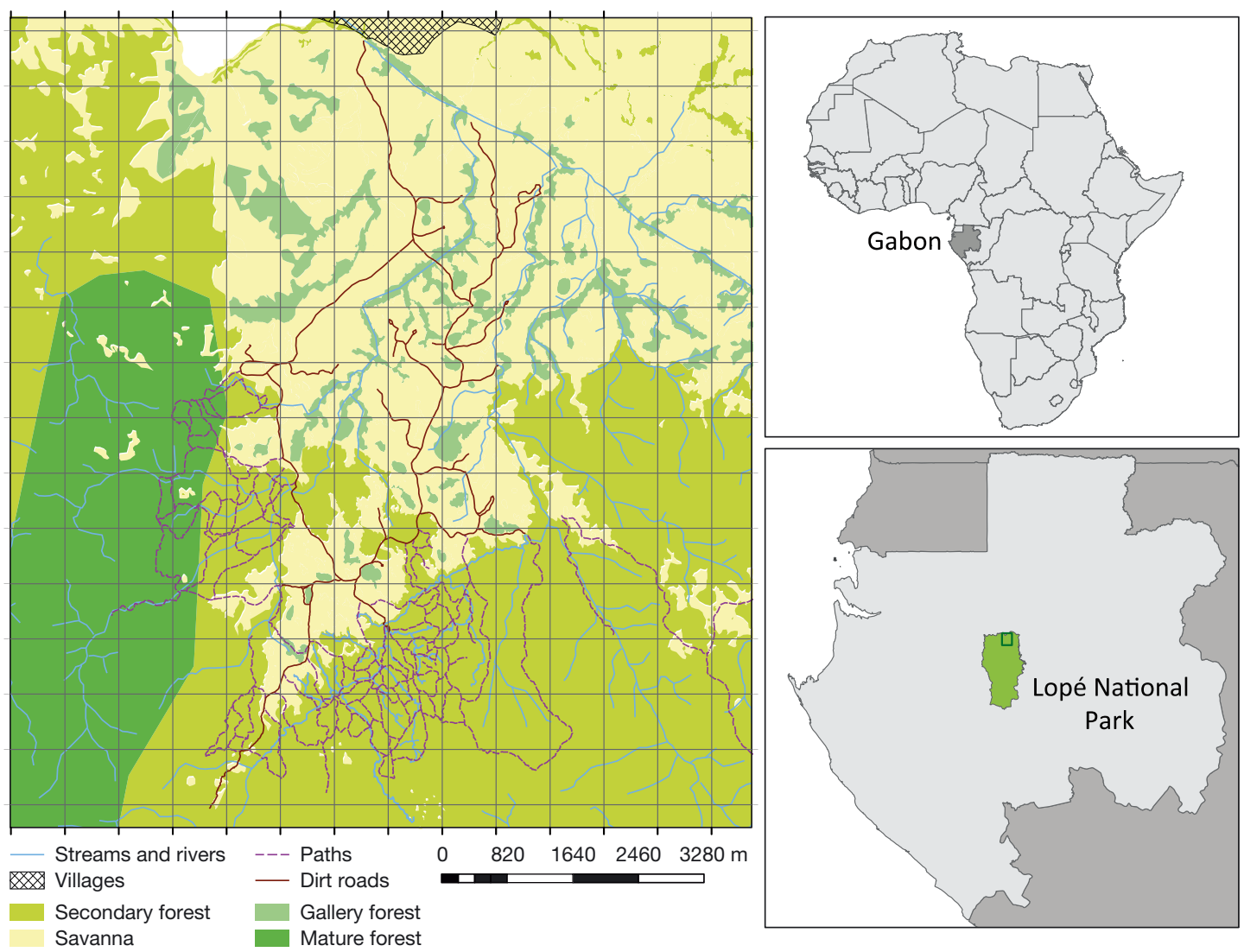

Fig. 1. Station d'Etudes des Gorilles et Chimpanzees (SEGC) study zone (left) from Schuttler et al. (2014). The green rectangle in Lopé National Park (LNP) represents the SEGC study zone area (bottom right)

vein patterns, tusks, and tail brushes) with reference to an existing database (Momont 2007). Groups were observed for 15 to $60 \mathrm{~min}$, depending on visibility of individuals. Date, time, number of individuals, and sex were recorded. Age-classes were estimated following standard methods (Turkalo 2013), and 2 ageclasses (juvenile, pre-reproductive; adult, reproductive) were used. Existing long-term data were used to confirm the ages of known adults $>15$ yr old (Momont 2007).

In 2008 and 2010, we collected fresh dung samples $(\leq 24 \mathrm{~h})$ for genetic analysis following Schuttler et al. (2014). Samples were imported into the United States under USDA (United States Department of Agriculture) Permit \#48529. Dung searches were conducted immediately after elephants had left the observation area, except for groups observed at dusk, when searches were delayed until the following morning. Few individuals were observed defecating, so it was possible that some dung samples belonged to members of other groups. To address this, we categorized dung samples as: (1) definite-individual is seen defecating or sample is collected immediately after elephant group has left; (2) probable - over time, the dung sample was collected repeatedly from the identified individual/group observed; (3) tentative - dung was collected after observations, but the individual was seen once or dung was collected from this individual once. We were confident most samples belonged to observed groups; there were usually fewer dung samples than observed group members; we used fresh tracks based on elephants' observation location to follow groups; and groups were usually separated by at least several kilometers. During observations, we rarely saw large groups or areas used by multiple groups; membership was uncertain in only a few groups $(2.9 \%)$. We averaged circumferences of 3 dung boli to estimate 2 age-classes: juvenile $(<30 \mathrm{~cm}$, pre-reproductive) and adult $(\geq 30 \mathrm{~cm}$, reproductive; Schuttler et al. 2014).

\section{DNA extraction and genetic analysis}

Methods for DNA extraction, microsatellite genotyping, molecular sexing, and sequencing of the 
mitochondrial DNA (mtDNA) are fully described in Schuttler et al. (2014). In summary, individuals were genotyped at 10 microsatellites. Homozygous genotypes were amplified 3 times for confirmation, while heterozygous genotypes were amplified twice. Only samples with positive results for at least 6 loci were retained for analyses. A $627 \mathrm{bp}$ fragment of the mtDNA control region was sequenced for unique individuals.

\section{Social networks}

From observational data, we computed simple ratio association indices (AI) as a measure of the strength of the relationships between dyads of adult females where $A I=N_{A B} /\left(N_{A}+N_{B}+N_{A B}\right) \cdot N_{A B}$ represents the number of times individuals $\mathrm{A}$ and $\mathrm{B}$ were seen together, while $\mathrm{N}_{\mathrm{A}}$ and $\mathrm{N}_{\mathrm{B}}$ represent each time that individual was seen without the other individual (Ginsberg \& Young 1992). We created networks to visualize associations using UCINET Version 6.415 (Borgatti et al. 2002) and NetDraw Version 2.122 (Borgatti 2002). Individuals are represented as nodes, associations are represented as connections between nodes (edges), and nodes connected to one another, but not connected to the rest of the network, are components. Networks included only identified adult females, as offspring are dependent on mothers.

We created several types of social networks to highlight important associations: (1) global, (2) preferred associates, (3) year, and (4) season. The global network represents all adult females and associations observed over all years to show the extent of social occurrences. The preferred associates network included individuals observed $\geq 2$ times and therefore more representative of an individual's behavior (de Silva et al. 2011). Preferred associations are those for which an AI value is at least 2 times more than the mean (Whitehead 2008). Year networks represent 2006, 2008, and 2010, and include individuals found during those years. Season networks investigate differences in associations between wet and dry seasons and combine data across years. Rainfall data were collected and recorded daily at SEGC. Months with higher total rainfall than the 3 yr monthly average were considered 'wet,' while those with less were considered 'dry.' As more observations were conducted in wet season months, to ensure equal sampling, we chose 3.5 mo worth of observational data from months occurring in the wet season (total rainfall $=703 \mathrm{~mm}$, monthly average $=234 \mathrm{~mm}$ ) to compare to data collected during the $3.5 \mathrm{mo}$ of the dry season (total rainfall $=74 \mathrm{~mm}$, monthly average $=$ $25 \mathrm{~mm}$ ).

We conducted linear regressions in EXCEL 14.3.5. to test the hypothesis that the number of times an individual was seen influenced the number of associates and maximum AI value. We also investigated the relationship between the number of observations and number of edges, maximum component size, and the number of edges in the largest component in the global network.

For individuals where genetic data were successfully generated, we estimated relatedness and added values to edges between dyads. Nodes were colored according to mitochondrial haplotype. Relatedness was calculated using the Queller-Goodnight moment estimator (Queller \& Goodnight 1989) in RELATEDNESS Version 5.0.8 (Queller \& Goodnight 1989) using bias correction (Schuttler et al. 2014).

We calculated the following network measures in UCINET: density, the ratio of edges that exist between nodes out of all that could exist; mean degree, the average number of edges a node is connected to; mean path length, the average shortest path for one node to connect to another (Croft et al. 2008); and clustering coefficient, i.e. the degree to which associates of an individual are associated within the network (Whitehead 2008).

We tested for preferred/avoided associations in SocProG Version 2.4 (Whitehead 2009) using $7 \mathrm{~d}$ sampling periods to test the null hypothesis that there are no preferred or avoided associations for the global and preferred networks. We chose $7 \mathrm{~d}$ because this was long enough to collect sufficient observations, but short enough to limit immigration/ emigration into the sampling area (Whitehead 2008). We permuted groups within samples and used a 2-tailed significance level of 0.05 with 1000 trials per permutation and 20000 permutations to determine the number of dyads preferred or avoided based on statistically significant high or low association indices. Twenty-thousand permutations were determined to be a sufficient number, indicated by stabilizing p-values (Bejder et al. 1998).

\section{RESULTS}

We identified 118 adult females, seen an average of 3.0 times (range: 1 to 34 , mode: 2). The number of new individuals increased as the number of identifications increased (Fig. S2 in the Supplement at www. int-res.com/articles/suppl/n025p165_supp.pdf). We were able to assign unique genotypes from dung 
samples to 40 individuals as definite $(\mathrm{n}=20)$, probable $(n=4)$, or tentative $(n=16)$, and 7 mtDNA haplotypes were identified (Schuttler et al. 2014).

Average observed group sizes ranged from 2.7 to 3.3 for all individuals and 1.3 to 1.6 when excluding dependent calves (Table 1). There was a bimodal pattern in association indices between dyads, with a large number of individuals having low and high AI values. When excluding individuals seen once, this pattern disappeared, with values being more equally represented (Fig. 2).

There was a weak, but statistically significant, correlation between the number of times an individual was seen and the number of associates it had $\left(R^{2}=0.104, p<0.001\right)$. This did not influence the maximum AI value for an individual $\left(\mathrm{R}^{2}=\right.$ 0.010, $\mathrm{p}=0.295$ ). Therefore, individuals observed more often were more likely to have more associates, but not stronger associations. After removing individuals seen once $(n=55)$, there was no significant relationship between the number of times an individual was seen and the number of associates it had $\left(R^{2}=0.030, p=0.200\right)$. However, there was a weak, but significant, correlation between the number of sightings and the maximum $\mathrm{AI}$ of an individual $\left(\mathrm{R}^{2}=0.076, \mathrm{p}=0.036\right)$. We found $\mathrm{a}$

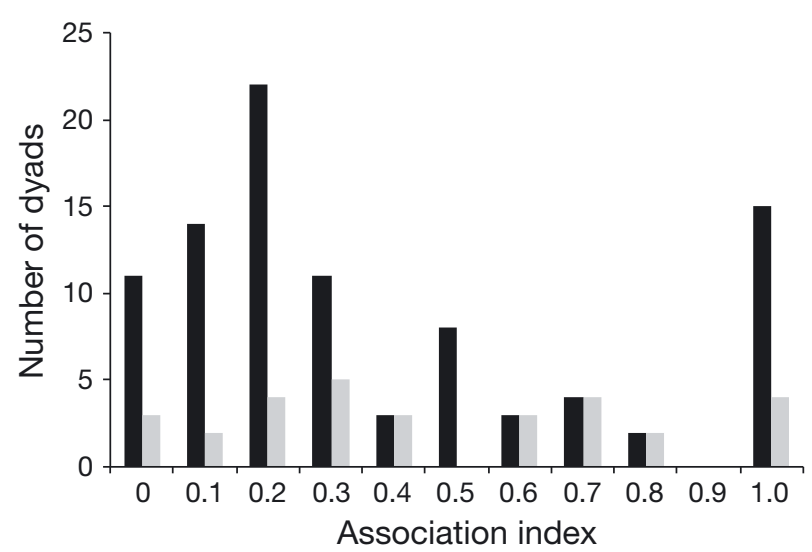

Fig. 2. Loxodonta cyclotis. Association index values in all adult female dyads observed (black bars) and dyads in which the adult females were observed 2 or more times (grey bars)

strong linear relationship between the number of observations and the number of edges added $\left(R^{2}=\right.$ $0.960, \mathrm{p}<0.001$ ) and between the number of observations and the maximum component size $\left(R^{2}=0.719, p<0.001\right)$, and the maximum number of edges within the largest component $\left(R^{2}=0.500\right.$, $\mathrm{p}<0.001)$.

Approximately one-quarter of the global network $(25.4 \%)$ was made up of solitary individuals (Table 2, Fig. 3a). There was 1 large component of 22 adult females of which all but 1 individual with genetic information shared the same haplotype. The next largest component was 4 individuals; 5 components of this size were detected in the network. The average relatedness of adult females within a component was $0.105 \pm 0.078$

Table 2. Loxodonta cyclotis. Network metrics from different observation periods of forest elephants in Lopé National Park. Definitions of metrics are given in 'Materials and methods: Social networks'

\begin{tabular}{|c|c|c|c|c|c|c|c|c|c|}
\hline $\begin{array}{l}\text { Social } \\
\text { network }\end{array}$ & Nodes & Edges & $\begin{array}{c}\text { Solitary } \\
\text { individuals }\end{array}$ & $\begin{array}{l}\text { Connected } \\
\text { components }\end{array}$ & $\begin{array}{c}\text { Largest } \\
\text { connected } \\
\text { component }\end{array}$ & Density & $\begin{array}{c}\text { Mean } \\
\text { degree }\end{array}$ & $\begin{array}{l}\text { Mean } \\
\text { path } \\
\text { length }\end{array}$ & $\begin{array}{l}\text { Clustering } \\
\text { coefficient }\end{array}$ \\
\hline Global & 118 & 97 & 30 & 27 & 22 & 0.014 & 1.664 & 2.275 & 0.804 \\
\hline $\begin{array}{l}\text { Preferred } \\
\text { associates }\end{array}$ & 63 & 65 & 8 & 17 & 17 & 0.033 & 2.063 & 2.157 & 0.857 \\
\hline Year 2006 & 43 & 19 & 6 & 14 & 5 & 0.034 & 1.442 & 1.167 & 0.870 \\
\hline Year 2008 & 58 & 28 & 21 & 15 & 4 & 0.018 & 1.000 & 1.125 & 0.822 \\
\hline Year 2010 & 68 & 59 & 20 & 16 & 14 & 0.026 & 1.735 & 1.836 & 0.832 \\
\hline Wet season & 52 & 56 & 15 & 15 & 4 & 0.021 & 1.077 & 1.125 & 0.897 \\
\hline Dry season & 29 & 24 & 8 & 10 & 3 & 0.049 & 1.379 & 1.091 & 0.933 \\
\hline
\end{tabular}




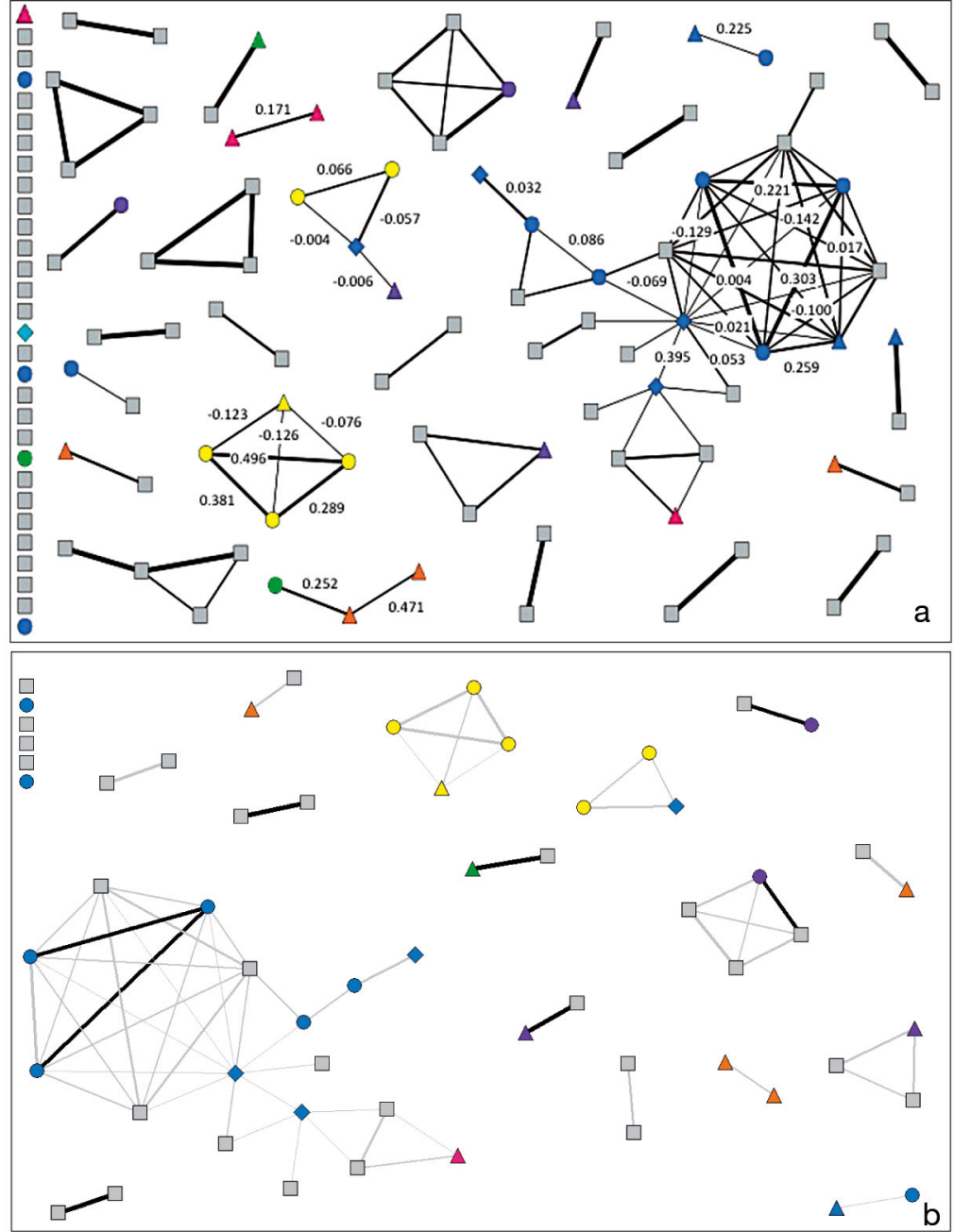

Fig. 3. Loxodonta cyclotis. (a) Global social network for adult females observed throughout the study. Edge width is associated with the simple ratio association index between dyads. Dyads with thicker edges have a higher association index. (b) Preferred associates social network, including only adult females seen 2 times or more. All associations are shown (grey), and black edges represent preferred associations, defined as those dyads with a simple ration association index at least 2 times the mean. For both networks, the shape of the node designates the certainty of the genetic sample collected for the individual $-\square$ : no genetic data available; O: definite; $\diamond$ : probable; $\Delta$ : tentative. The color of the node indicates the mitochondrial haplotype associated with the sample-grey: haplotype is absent; pink: Lope1; orange: Lope3; yellow: Lope4; green: Lope5; aqua: Lope6; blue: Lope7; purple: Lope9

(SD), with a range of 0.031 to 0.180 (SD). Average relatedness of dyads was $0.104 \pm 0.190$ (SD).

The networks for each year included solitary individuals. The largest components for 2006 and 2008 contained 5 and 4 individuals, respectively, while 2010 contained 1 large component of 14 individuals (Table 2). This component was largely due to an observation of the largest group, containing 22 individuals (8 adult females).
The preferred associates network included a large component of 17 adult females, including adult females not present in the global group of 22 individuals (Table 2, Fig. 3). Fifty-five individuals were seen once during the study and were removed from the preferred associates network (Table 2, Fig. 3). Almost half of these females $(n=23)$ were solitary, accompanied only by juveniles. The mean AI for dyads in the preferred association network was $0.339 \pm 0.270(\mathrm{SD})$, and few preferred associations (those $\geq 0.679$ ) were identified (8 of 65 associations, $12.3 \%$ ) overall (Fig. 3b).

Rainfall data from SEGC are shown in Fig. S1 in the Supplement. There were no clear differences between dry and wet season networks (Table 2). The wet season network included more individuals, but not larger components. The largest component in both networks consisted of 4 females. The wet season network had a larger number of solitary individuals (15 versus 8), but also had more individuals overall.

All networks had low densities (range: 0.014 to 0.049 ) and short average path lengths (1.091 to 2.275 ) due to many disconnected components (Table 2). Mean degrees, reflecting the number of associates an individual has, were also low (1.000 to 2.063), but clustering coefficients were high (0.804 to 0.933 ; Table 2 ).

Global and preferred networks showed mean levels of association that were significantly different from those expected by chance (Table 3 ). The standard deviation (SD) and coefficient of variation (CV) of the AIs were also significantly higher than expected values, indicating that individuals preferentially associate across sampling periods. However, only a few dyads were non-randomly associated (global: 23 of 345 expected, $6.7 \%$; preferred: 19 of 104 expected, $18.3 \%$ ) as indicated by the low number of significant dyads with preferred associations ( $p>0.975)$. There was no evidence that certain dyads were avoided $(p<0.025)$, but the proportion of nonzero association indices was lower in the observed data than in the expected data, suggesting that some individuals avoid others (Table 3). 
Table 3. Loxodonta cyclotis. Observed and expected association indices (simple ratio association index, AI) for all adult females sighted (global) and for adult females observed 2 times or more (preferred). Values in bold are significant at $\mathrm{p}<0.05$

\begin{tabular}{|c|c|c|c|}
\hline & \multicolumn{2}{|c|}{$\longrightarrow$ Simple ratio $\mathrm{AI}-$} & \multirow[t]{2}{*}{$\mathrm{p}$} \\
\hline & Observed & Expected & \\
\hline \multicolumn{4}{|l|}{ Global } \\
\hline Mean & 0.007 & 0.005 & 0.998 \\
\hline $\mathrm{SD}$ & 0.068 & 0.049 & 1.000 \\
\hline $\mathrm{CV}$ & 10.020 & 9.340 & 0.998 \\
\hline Nonzero & 0.014 & 0.024 & 0.001 \\
\hline \multicolumn{4}{|l|}{ Preferred } \\
\hline Mean & 0.013 & 0.010 & 1.000 \\
\hline SD & 0.086 & 0.048 & 1.000 \\
\hline $\mathrm{CV}$ & 6.576 & 4.843 & 1.000 \\
\hline Nonzero & 0.033 & 0.067 & 0.001 \\
\hline
\end{tabular}

\section{DISCUSSION}

Our study presents the first inference of African forest elephant social networks from observational data. The networks exhibit fission-fusion dynamics, but are different in structure from African savanna and Asian species. We detected a component ( $\mathrm{n}=22$ adult females) larger in size than any forest elephant group observed in any population (White et al. 1993, Morgan \& Lee 2007, Turkalo et al. 2013). Overall, though, networks were disconnected, with many small components, including many solitary females with no differences in structure between seasons. Few individuals had preferred associations, and those that existed were mostly between dyads, and were not interconnected as larger components. Components and associations appeared to be based on matrilines and kinship, consistent with previous studies (Munshi-South 2011, Schuttler et al. 2014), although average component relatedness (0.105 \pm $0.078, \mathrm{SD})$ was lower than the mean group relatedness in savanna elephants Loxodonta africana (0.150: Archie et al. 2006; 0.234: Wittemyer et al. 2009).

The global network for forest elephants differs greatly from those for African savanna and Asian elephant populations. The savanna elephant population was connected as a single component of 89 females (Archie \& Chiyo 2012). Even when filtering associations and including only individuals spending $>10 \%$ of their time together, large components still exist (5 to 13 adult females). In the Asian elephant population, despite observed smaller group sizes (2.8 to 3.0 adult females), population-level networks consisted of 5 to 10 components, plus solitary individuals (de Silva et al. 2011), which was more disconnected than the savanna elephant population, but more connected than our global network of 27 components and 30 solitary individuals.

The networks also vary in sampling and the number of times individuals were seen, which can impact structure and present a source for the differences detected. Savanna elephants were observed for 36 mo (recapture values not included); Asian elephants for $20 \mathrm{mo}$, with 9 as the mode recapture rate; and forest elephants for approximately $15 \mathrm{mo}$, with a low recapture rate (mode of 2). The preferred associates network included higher recaptures and likely better characterization of forest elephant sociality. One large component was still present in this network $(\mathrm{n}=17)$, and there were fewer solitary individuals. However, this network had fewer females compared to other studies ( $\mathrm{n}=63$, this study; $\mathrm{n}=89$, savanna elephants; $\mathrm{n}=154$ to 201, Asian elephants). Adding more observations may alter network structure; the number of associates increased with the number of observations, and significant correlation was found between the number of observations and the edges added. New individuals were identified throughout the study and possibly confounded these relationships. However, an increasing number of observations added new individuals to the network, but did not heighten network complexity. More components containing dyads were added than edges between existing individuals. Furthermore, there was no influence on the number of times an individual was seen on its maximum AI value. Further research is needed to evaluate these relationships.

The largest component observed in the network may result from sampling in the savannas, possibly representing a more complete group of individuals, while smaller components may represent subsets of groups at the edges of their range. Telemetry studies in LNP and the ecologically similar Loango NP, Gabon, found home ranges to be small, 9 to $343 \mathrm{~km}^{2}$ (Momont 2007) and 11 to $105 \mathrm{~km}^{2}$ (Schuttler et al. 2012), respectively, and, in LNP, 1 'resident' elephant remained in a small, northeastern section of the park. Additionally, Fishlock \& Lee (2013) found that forest elephants maximize social opportunities at mineral resources, staying longer and joining larger groups. Increasing the sampling area, in addition to recapturing individuals, may increase connections between those individuals at range edges and more large components may be detected.

Perhaps the greatest influence on network structure is poaching, which has reached crisis levels in Central Africa (Blake et al. 2007, Maisels et al. 2013). 
Gobush et al. (2009) found smaller savanna elephant groups (means of 2 adult females) and a large presence of solitary females $(30 \%)$ in the heavily poached population of Mikumi National Park, Tanzania. Poaching may have disrupted forest elephant social structure by removing individuals, thus reducing associations. However, individuals in the Mikumi population grouped with non-kin, which was not strongly observed in this study or in that of Schuttler et al. (2014).

Finally, ecological and environmental factors also likely have a large influence on forest elephant social structure and the differences observed between the species. Even with additional observations, it is unlikely that forest elephant networks will reach the level of complexity of savanna elephants over the same time period. In chimpanzees, the advantages of fission-fusion sociality lie in reducing the costs of moving; by splitting into smaller parties during foraging, individuals are able to reduce moving time, which reduces energy demand and feeding time (Lehmann et al. 2007). As the diets of forest elephants and chimpanzees overlap substantially (White et al. 1994), the spatial patchiness of and ephemeral nature of forest fruits may have similar influences on forest elephants, favoring small groups. Smaller group sizes and fewer permanent associations have also been observed in the savanna elephants of Namibia, which may be a result of another environmental constraint, an extreme desert environment (Leggett et al. 2003). Further research is needed to fully evaluate the influence of habitat on social structure in elephants.

\section{CONCLUSIONS}

We found that forest elephants have fission-fusion patterns of sociality, but, as a population, individuals are largely disconnected from one another; this differs from the social structure in Asian and African savanna species. Great variation occurs within the population, with some elephants having many associates, while others remain solitary. Although genetic data were sparse, they suggest most associations are based on matrilineal kinship, consistent with savanna elephant populations and previous studies on forest elephants. Forest elephants, therefore, appear to differ from the other elephant species, overall with more fragmented networks, fewer associations, and more solitary individuals. However, due to low re-sightings of individuals within this population, we recommend further research for future comparisons.
Acknowledgements. We thank the Gabonese government, Centre National de la Recherche Scientifique et Technologique, and Agence Nationale des Parcs Nationaux for permission to work in Lopé National Park, Station D'Etudes des Gorilles et Chimpanzes, and Centre International de Recherches Medicales de Franceville for providing institutional and logistical support for fieldwork, and the United States Fish and Wildlife Service African Elephant Conservation Fund (Agreement \#98210-8-G753 to L.S.E.), the University of Missouri (MU) Life Sciences fellowship, MU Conservation Biology fellowship, TransWorld Airline scholarship, and Graduate STEM (science, technology, engineering, and mathematics) Fellows in K-12 Education grant funding (National Science Foundation \#045322) for financial support. We thank L. Momont, L. White, and K. Abernathy for advice on logistics and research in LNP. J. Dibakou, J. T. Dikangadissi, E. Dimoto, and C. Nzotekoumie provided invaluable logistical support and guidance in the field.

\section{LITERATURE CITED}

Archie EA, Chiyo PI (2012) Elephant behaviour and conservation: social relationships, the effects of poaching, and genetic tools for management. Mol Ecol 21:765-778

Archie EA, Moss CJ, Alberts SC (2006) The ties that bind: genetic relatedness predicts the fission and fusion of social groups in wild African elephants. Proc R Soc B 273:513-522

Bejder L, Fletcher D, Brager S (1998) A method for testing association patterns of social animals. Anim Behav 56: 719-725

Blake S, Strindberg S, Boudjan P, Makombo C and others (2007) Forest elephant crisis in the Congo Basin. PLoS Biol 5:e111

Borgatti SP (2002) NetDraw software for network visualization. Analytic Technologies, Lexington, KY

Borgatti SP, Everett MG, Freeman LC (2002) Ucinet for Windows: software for social network analysis. Analytic Technologies, Harvard, MA

> Campos-Arceiz A, Blake S (2011) Megagardeners of the forest-the role of elephants in seed dispersal. Acta Oecol 37:542-553

Croft DP, James R, Krause J (2008) Exploring animal social networks. Princeton University Press, Princeton, NJ

> Croft DP, Madden JR, Franks DW, James R (2011) Hypothesis testing in animal social networks. Trends Ecol Evol 26:502-507

> de Silva S, Ranjeewa A, Kryazhimskiy S (2011) The dynamics of social networks among female Asian elephants. BMC Ecol 11:17

Fishlock V, Lee PC (2013) Forest elephants: fission-fusion and social arenas. Anim Behav 85:357-363

Fishlock V, Lee PC, Breuer T (2008) Quantifying forest elephant social structure in Central African bai environment. Pachyderm 44:17-26

Ginsberg JR, Young TP (1992) Measuring association between individuals or groups in behavioural studies. Anim Behav 44:377-379

Gobush KS, Mutayoba B, Wasser SK (2008) Long-term impacts of poaching on relatedness, stress physiology, and reproductive output of adult female African elephants. Conserv Biol 22:1590-1599

Gobush K, Kerr BEN, Wasser S (2009) Genetic relatedness and disrupted social structure in a poached population of African elephants. Mol Ecol 18:722-734 
Hamede RK, Bashford J, McCallum H, Jones M (2009) Contact networks in a wild Tasmanian devil (Sarcophilus harrisii) population: using social network analysis to reveal seasonal variability in social behaviour and its implications for transmission of devil facial tumour disease. Ecol Lett 12:1147-1157

Hoelzel A (1993) Foraging behaviour and social group dynamics in Puget Sound killer whales. Anim Behav 45: 581-591

Kerth G, Konig B (1999) Fission, fusion and nonrandom associations in female Bechstein's bats (Myotis bechsteinii). Behaviour 136:1187-1202

Krebs JR, Davies NB (1997) Behavioural ecology: an evolutionary approach. Blackwell Publishing, Oxford

> Lee PC (1987) Allomothering among African elephants. Anim Behav 35:278-291

Leggett K, Fennessy J, Schneider S (2003) Seasonal distributions and social dynamics of elephants in the Hoanib River catchment, northwestern Namibia. Afr Zool 38: 305-316

> Lehmann J, Boesch C (2004) To fission or to fusion: effects of community size on wild chimpanzee (Pan troglodytes verus) social organisation. Behav Ecol Sociobiol 56: 207-216

Lehmann J, Korstjens AH, Dunbar RIM (2007) Fissionfusion social systems as a strategy for coping with ecological constraints: a primate case. Evol Ecol 21:613-634

Maisels F, Strindberg S, Blake S, Wittemyer G and others (2013) Devastating decline of forest elephants in Central Africa. PLoS ONE 8:e59469

McComb K, Moss CJ, Durant SM, Baker L, Sayialel S (2001) Matriarchs as repositories of social knowledge in African elephants. Science 292:491-494

McComb K, Shannon G, Durant SM, Sayialel K, Slotow R, Poole J, Moss C (2011) Leadership in elephants: the adaptive value of age. Proc Biol Sci 278:3270-3276

Momont L (2007) Sélection de l'habitat et organisation sociale de l'éléphant de forêt, Loxodonta africana cyclotis (Matschie 1900), au Gabon. Muséum National d'Histoire Naturelle, Paris

> Morgan BJ, Lee PC (2007) Forest elephant group composition, frugivory and coastal use in the Réserve de Faune du Petit Loango, Gabon. Afr J Ecol 45:519-526

Moss CJ (1988) Elephant memories. University of Chicago Press, Chicago, IL

Munshi-South J (2011) Relatedness and demography of African forest elephants: inferences from noninvasive fecal DNA analyses. J Hered 102:391-398

Ortega J, Maldonado JE, Wilkinson GS, Arita HT, Fleischer RC (2003) Male dominance, paternity, and relatedness in the Jamaican fruit-eating bat (Artibeus jamaicensis). Mol Ecol 12:2409-2415

> Parra GJ, Corkeron PJ, Arnold P (2011) Grouping and fission-fusion dynamics in Australian snubfin and IndoPacific humpback dolphins. Anim Behav 82:1423-1433

> Prins HHT (1989) Buffalo herd structure and its repercussions for condition of individual African buffalo cows. Ethology 81:47-71

> Queller DC, Goodnight K (1989) Estimating relatedness using genetic markers. Evolution 43:258-275

> Rohland N, Reich D, Mallick S, Meyer M and others (2010) Genomic DNA sequences from mastodon and woolly mammoth reveal deep speciation of forest and savanna elephants. PLoS Biol 8:e1000564

Rossiter SJ, Zubaid A, Mohd-Adnan A, Struebig MJ and others (2012) Social organization and genetic structure: insights from codistributed bat populations. Mol Ecol 21: $647-661$

Schuttler SG, Blake S, Eggert LS (2012) Movement patterns and spatial relationships among African forest elephants. Biotropica 44:445-448

Schuttler SG, Philbrick JA, Jeffery KJ, Eggert LS (2014) Fine-scale genetic structure and cryptic associations reveal evidence of kin-based sociality in the African forest elephant. PLoS ONE 9:e88074

Shannon G, Slotow R, Durant S, Sayialel K, Poole J, Moss C, McComb K (2013) Effects of social disruption in elephants persist decades after culling. Front Zool 10:62-72

Sih A, Hanser SF, McHugh K (2009) Social network theory: new insights and issues for behavioral ecologists. Behav Ecol Sociobiol 63:975-988

Sukumar R (2003) The living elephants: evolutionary ecology, behavior, and conservation. Oxford University Press, New York, NY

> Turkalo AK (2013) Estimating forest elephant age. Afr J Ecol 51:501-505

Turkalo A, Fay JM (1996) Studying forest elephants by direct observation: preliminary results from the Dzanga clearing, Central African Republic. Pachyderm 21:45-54

Turkalo AK, Wrege PH, Wittemyer G (2013) Long-term monitoring of Dzanga Bai forest elephants: forest clearing use patterns. PLoS ONE 8:e85154

> Weimerskirch H, Bertrand S, Silva J, Marques JC, Goya E (2010) Use of social information in seabirds: compass rafts indicate the heading of food patches. PLoS ONE 5: e9928

Wey T, Blumstein DT, Weiwei S, Jordan F (2008) Social network analysis of animal behaviour: a promising tool for the study of sociality. Anim Behav 75:333-344

> White LJT (1994) Biomass of rain-forest mammals in the Lopé Reserve, Gabon. J Anim Ecol 63:499-512

White LJT, Tutin CG, Fernandez M (1993) Group composition and diet of forest elephants, Loxodonta africana cyclotis Matschie 1900, in the Lopé Reserve, Gabon. Afr J Ecol 31:181-199

White LJT, Tutin CEG, Fernandez M (1994) Behavioural and dietary similarities of elephants and apes in the Lopé Reserve, Gabon: Should forest elephants be re-classified as apes? In: Thierry B, Anderson JR, Roeder JJ, Herrenschmidth N (eds) Current primatology, Vol 1. Ecology and evolution. Université Louis Pasteur, Strasbourg

Whitehead H (2008) Analyzing animal societies: quantitative methods for vertebrate social analyses. University of Chicago Press, Chicago, IL

- Whitehead H (2009) SOCPROG programs: analyzing animal social structures. Behav Ecol Sociobiol 63:765-778

> Willis CKR, Brigham RM (2005) Roost switching, roost sharing and social cohesion: forest-dwelling big brown bats, Eptesicus fuscus, conform to the fission-fusion model. Anim Behav 69:495-505

Wittemyer G, Douglas-Hamilton I, Getz WM (2005) The socioecology of elephants: analysis of the processes creating multitiered social structures. Anim Behav 69:1357-1371

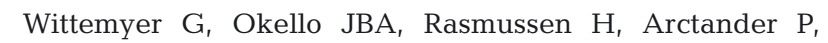
Nyakaana S, Douglas-Hamilton I, Siegismund HR (2009) Where sociality and relatedness diverge: the genetic basis for hierarchical social organization in African elephants. Proc Biol Sci 276:3513-3521

Wrangham RW (1980) An ecological model of femalebonded primate groups. Behaviour 75:262-300 